\title{
Mecanismos básicos de la propaganda de guerra en los medios informativos. El ejemplo de Kosovo.
}

\author{
María José García Orta \\ Grupo de Investigación en Estructura, Historia y Contenidos de la Comunicación
}

\section{RESUMEN}

Este artículo describe los mecanismos e instrumentos básicos de la propaganda que son utilizados por los medios de comunicación occidentales en tiempos de guerra, mecanismos que contribuyen a obtener la aceptación y el apoyo de la opinión pública a acciones concretas. Cada una de las estrategias básicas está ilustrada con ejemplos obtenidos del periódico El País durante el conflicto de Kosovo.

\section{ABSTRACT}

This article describes to the mechanisms and basic instruments of the propaganda that are used by western mass media in the days of war. These mechanisms contribute to obtain the acceptance and the support of the public opinion. Examples obtained of El Pais during the conflict of Kosovo inform about each one of the basic strategies.

Palabras claves: Propaganda/ Propaganda de guerra/ Medios de comunicación/ Kosovo.

Key Words: Propaganda/ Psychologial Warfare/ Media/ Kosovo.

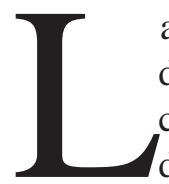

a propaganda se ha convertido en uno de los fenómenos más importantes de nuestro siglo. Su utilización es ya frecuente en diversos ámbitos, como las campañas electorales. Incluso los gobiernos de algunos países destinan anualmente importantes sumas de dinero para contratar personas que difundan mensajes que les sean favorables.

Este boom experimentado por la propaganda desde comienzos del siglo XX ha ido unido al desarrollo de los medios de comunicación de masas, que en determinados momentos históricos la han empleado para satisfacer intereses concretos. Y es que, como afirma María Victoria Reyzábal, "su utilización como forma de controlar el flujo de información, modelar la opinión pública o manipular el comportamiento es tan vieja como la historia misma"'.

1 REYZÁBAL, María Victoria: Propaganda y manipulación. Acento Editorial, Madrid, 1999, p. 81. 
138 Mecanismos básicos de la propaganda de guerra en los medios informativos.

El ejemplo de Kosovo

En este sentido, podemos afirmar que la propaganda nace al mismo tiempo que los primeros intentos de organización social, aunque el término ${ }^{2}$ no aparece hasta el siglo XVII y lo hace ligado a la acción de dar a conocer y propagar doctrinas y creencias religiosas, extendiéndose más tarde al terreno político.

Más concretamente, la propaganda de guerra (denominada por los británicos Psychological Warfare) existe desde que comenzaron los conflictos, por muy rudimentarios que nos parezcan en la actualidad los procedimientos que utilizaban. En efecto, desde siempre se ha intentado intimidar al enemigo, exaltar lo positivo y ocultar o justificar las propias derrotas, etc.

Tal es la relación entre la propaganda y los conflictos bélicos, que Pizarroso Quintero afirma que "quizá en tiempos de guerra o de conflicto agudo es cuando

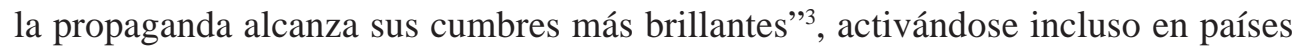
donde, en apariencia, la propaganda estatal no existe en tiempos de paz. Y esto es así porque "la propaganda de guerra sería la continuación de la propaganda política en otra situación. De hecho, la propaganda y la guerra tienen análogos objetivos. La guerra es "un acto de violencia encaminado a forzar al adversario a someterse a nuestra voluntad ". Parafraseando, podríamos decir que la propaganda es un acto de violencia mental para forzar a alguien a someterse a nuestra voluntad" 4 .

Pronto, la difusión de historias sobre las crueldades cometidas por el enemigo -independientemente de que respondieran o no a la realidad-, contribuyó al desprestigio del término, desprestigio que se acentuó durante el régimen de Hitler en Alemania. De hecho, Domenach destaca que "el uso que de ella hicieron los nazis nos acostumbró a considerar la propaganda como un método de perversión y de mentira. Esta reacción, en el fondo, es sana; pero sus consecuencias son temibles, pues la propaganda, que es una función política natural, se hace vergonzante, se mezcla entonces en la información y se oculta detrás de las "noticias" y las estadísticas"

En la actualidad, esta carga peyorativa ha propiciado la sustitución del término propaganda por eufemismos como 'publicidad política'o 'comunicación política', pero no ha impedido que los medios de comunicación sigan utilizando recursos propagandísticos en sus informaciones, contribuyendo con su uso a legitimar ciertas acciones, como puede ser la intervención en un conflicto armado. Precisamente este

2 Son muchos los autores que consideran que el término proviene de la locución latina De Propaganda Fide ('Acerca de la propagación de la fe'), el nombre de la congregación vaticana Sacra Congregatio de Propaganda FIDE, constituida en 1622 por el Papa Gregorio XV para difundir la fe católica.

3 PIZARROSO QUINTERO, Alejandro: Historia de la propaganda. Notas para un estudio de la propaganda política y de 'guerra'. EUDEMA, Madrid, 1990, p. 35.

4 Ibídem, p. 34.

5 DOMENACH, Jean Marie: La propaganda política. Editorial Universitaria de Buenos Aires, Argentina, 1986.p. 105. 
artículo describe cuáles son los mecanismos básicos de la propaganda utilizados por los medios occidentales en tiempos de guerra, con el fin de ofrecer al lector los instrumentos necesarios para que analice de forma crítica el contenido que le ofrecen diariamente esos medios. Para ello, es necesario definir primero qué entendemos por propaganda y a continuación establecer sus principales estrategias, estrategias generales de la propaganda política que se pueden aplicar al tratamiento de cualquier conflicto. En nuestro caso, hemos optado por ilustras los mecanismos de la propaganda con ejemplos extraídos del diario El País durante el tratamiento del conflicto de Kosovo de 1999, ejemplos que evidencian cómo un medio recurre a la propaganda para dar una visión determinada de la guerra.

\section{Concepto y peculiaridades de la propaganda.}

El término propaganda es difícil de definir, ya que posee límites poco precisos. Así lo afirma Brown: "Está claro que los matices cambiantes de su

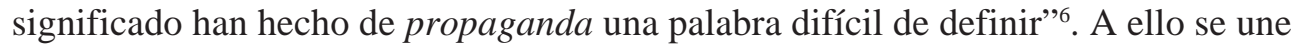
el hecho de que el término ha gozado de mala prensa en las últimas décadas, por lo que han proliferado las definiciones con carga ideológica. A pesar de todo, recogemos de forma esquemática aquellas definiciones que aportan los rasgos específicos de la propaganda.

La definición más inmediata que ofrecen muchos autores es la que considera a la propaganda como la acción de difundir y dar a conocer ideas. Sin embargo, Pizarroso Quintero da otra definición más elaborada:

"La propaganda, en el terreno de la comunicación social, consiste en un proceso de diseminación de ideas a través de múltiples canales con la finalidad de promover en el grupo al que se dirige los objetivos del emisor no necesariamente favorables al receptor; implica, pues, un proceso de información y un proceso de persuasión. Y podemos glosarla del siguiente modo: control del flujo de la información, dirección de la opinión pública y manipulación -no necesariamente negativa- de conductas $\mathrm{y}$, sobre todo, de modelos de conducta"?

Con estas palabras el autor destaca una de las características principales de la actividad propagandística, ya que se refiere a ella como un proceso de información y persuasión ${ }^{8}$, que persigue suscitar emociones de aprobación o rechazo en

6 BROWN, J.A.C.: Técnicas de persuasión. De la propaganda al lavado de cerebro. Alianza Editorial, Madrid, 1995, p. 12.

7 PIZARROSO QUINTERO, Alejandro: Op. cit., p. 28.

8 La persuasión es un proceso comunicativo que se realiza de forma consciente y cuyo principal objetivo es influir en otras personas. Kathleen Reardon la define como "la actividad de demostrar y de intentar modificar la conducta de por lo menos una persona mediante la interacción simbólica. Es una actividad consciente y se produce (a) cuando se registra una amenaza contra los objetivos de una persona y (b) cuando la fuente y el grado de esta amenaza son suficientemente importantes como para justificar el coste del esfuerzo que entraña la persuasión” (REARDON, Kathleen: La persuasión en la comunicación. Teoría y contexto. Ediciones Paidós Comunicación, Barcelona, 1983, p. 31). 
140 Mecanismos básicos de la propaganda de guerra en los medios informativos.

El ejemplo de Kosovo

torno a determinadas ideas que se corresponden con los objetivos del emisor o propagandista.

Por tanto, se deduce que no es conveniente identificar persuasión con propaganda, ya que no toda comunicación persuasiva se realiza con fines propagandísticos. Así lo entiende también Adrián Huici, para quien "si bien es posible que exista un proceso persuasivo que no implique el concepto de propaganda, no ocurre así al contrario, es decir: que no se concibe la propaganda o la publicidad comercial sin un componente de persuasión, sea éste manifiesto u oculto".

Young insiste en el cambio de actitud que pretende conseguir el propagandista, quien, a juicio de este autor, puede declarar abiertamente sus intenciones u ocultarlas. De hecho, define la propaganda como:

“(...) el uso deliberado de métodos de persuasión y otras técnicas simbólicas a fin de cambiar actitudes y a la postre influir sobre la acción (...). Uso más o menos deliberado, planeado y sistemático de símbolos, principalmente mediante la sugestión y otras técnicas psicológicas conexas con el propósito, en primer lugar, de alterar y controlar las opiniones, ideas y valores, y en último término, de modificar la acción manifiesta según ciertas líneas predeterminadas. La propaganda puede ser abierta y tener un propósito declarado o puede ocultar sus intenciones. Siempre se mueve en una estructura sociocultural determinada, sin la cual no pueden comprenderse sus aspectos psicológicos y culturales" 10 .

María Victoria Reyzábal ${ }^{11}$ completa las definiciones anteriores y añade que la propaganda es una forma de comunicación masiva, que se dirige, a través de los medios de comunicación de masas, a un público heterogéneo y disperso geográficamente. Como forma de comunicación masiva, define la propaganda con cinco rasgos esenciales, que constituyen, a nuestro juicio, la definición más completa que se ha ofrecido del término ${ }^{12}$. Esos rasgos son:

1. Es una comunicación persuasiva con fines predeterminados: Es una acción (comunicación) deliberada y planificada por un individuo o grupo activo (fuente o emisor) encaminada a conseguir la puesta en marcha de los mecanismos del sistema conductual del sujeto o grupo pasivo (receptor), para lograr que se produzca en él la conducta deseada por la fuente. Por lo tanto, la comunicación propagandística se ciñe siempre a los

9 HUICI MÓDENES, Adrián: Estrategias de la persuasión. Mito y propaganda política. Ediciones Alfar, Sevilla, 1996, p. 41.

10 YOUNG, K.: Psicología social de la propaganda. Ediciones Paidós Comunicación, Buenos Aires, 1969, p. 201.

11 REYZÁBAL, María Victoria: Op. cit., p. 33.

12 Ibídem, pp. 38-40. 
intereses del emisor, que realiza un intento deliberado de influencia, no sólo comunicando ciertas informaciones, sino también alterando el contenido de las mismas.

2. Tiene carácter impersonal. La propaganda concibe al receptor de forma impersonal, es enfocado como sujeto colectivo y dominado por sus afectos.

3. Su contenido es ideológico. Los contenidos y la temática de la propaganda pertenecen siempre a categorías ideológicas (políticas, religiosas, filosóficas...) o se refieren a grupos con unas ideologías determinadas. Es en el contenido ideológico y político donde los teóricos establecen la distinción entre propaganda y publicidad, aunque reconocen que determinar la relación y las diferencias entre ambas no resulta sencillo, ya que en la actualidad lo político y lo comercial se asemejan cada día más, hasta el punto de que un candidato político 'se vende' con las mismas técnicas utilizadas por la publicidad comercial.

4. Pretende la perpetuación o el cambio en las estructuras de poder. La intencionalidad de toda propaganda puede resumirse en el siguiente objetivo: conquistar o mantener el poder. Si éste no se posee, se aspira a lograrlo, enfrentándose a quien lo detente. Si el emisor ya posee el poder, su propaganda se encaminará a conseguir la afirmación y perpetuación en el mismo.

5. Persigue provocar la congruencia en el persuadido. Intenta que pensamiento y acción sean concordantes. De esta forma, una vez aceptada la propuesta contenida en el mensaje propagandístico, el individuo tenderá a eliminar las contradicciones, si las hubiese, entre el contenido del mensaje y su conducta posterior.

En definitiva, la propaganda es un proceso comunicativo -un proceso de información y persuasión-, de contenido ideológico, que persigue modificar las actitudes de las personas a las que se dirige, con objeto de adecuarlas a los objetivos deseados. Se trata de un proceso planificado previamente por el propagandista, que generalmente mantiene ocultas sus intenciones y utiliza múltiples canales y medios para conseguir sus fines.

En la actualidad los recursos de la propaganda son tan diversos que resultaría imposible hacer una sistematización exhaustiva. Domenach asegura que "la propaganda es polimorfa y cuenta con recursos casi ilimitados (...). El verdadero propagandista, el hombre que quiere convencer, aplica toda suerte de fórmulas, 
142 Mecanismos básicos de la propaganda de guerra en los medios informativos.

El ejemplo de Kosovo

según la naturaleza de la idea y la de sus oyentes"13. Por esta razón, hemos establecido cuatro mecanismos básicos de la propaganda que utilizan los medios para tratar las informaciones bélicas y fortalecer el efecto persuasivo de sus mensajes: la simplificación de la información, la exageración y desvirtuación de los contenidos, la apelación a la emoción y el tratamiento desequilibrado de las fuentes.

Sin embargo, dentro de estas reglas generales mencionamos otros recursos propagandísticos más específicos, que aparecen con cierta frecuencia en los medios de comunicación impresos, y que vienen a concretar cada una de las estrategias básicas. Para ello, hemos recurrido principalmente a la clasificación realizada por Merril ${ }^{14}$ y otros autores en la obra Medios de comunicación social. Teoría y práctica en Estados Unidos y en el mundo. Veamos con detenimiento los cuatro mecanismos esenciales.

\section{La simplificación de la información: el enemigo único y la personalización del adversario.}

La información en tiempos de guerra utiliza la simplificación como principal recurso propagandístico, lo que se traduce en la personificación del conflicto y en la dicotomización exagerada de la información procedente de los distintos bandos. La información se reduce al mínimo, por ejemplo, en un eslogan o en un símbolo, prescindiendo de cualquier argumentación racional.

El principal recurso de la simplificación es la identificación de un enemigo. $\mathrm{Al}$ respecto, Pizarroso Quintero señala que "la propaganda debe concentrarse en un solo objetivo (regla del único enemigo): hay que localizar un enemigo -una persona, un grupo, un país- y contra él concentrar todos los argumentos. Del mismo modo, la exaltación debe concentrarse en una persona o en un grupo." ${ }^{15}$.

De hecho, durante la cobertura del conflicto de Kosovo El País se hace eco de las declaraciones de políticos occidentales que achacan al presidente Slobodan Miloseivc toda la responsabilidad de la situación en la que se encuentra la República Federal de Yugoslavia, con lo que el conflicto se personifica en él. Son numerosos los ejemplos al respecto: "El presidente Aznar, en una declaración desde Berlín poco después de las once de la noche, señaló que "la comunidad internacional tenía el deber de reaccionar". "El Gobierno de España confía en que Milosevic, sobre quien recae toda la responsabilidad de esta situación, reconsidere su postura y se avenga a la solución pacífica que la comunidad internacional ha promovido "” (25-3-1999, portada); "La UE responsabiliza a Milosevic del con-

13 DOMENACH, Jean Marie: Op. cit., p. 48.

14 MERRIL, John C., y otros: Medios de comunicación social. Teoría y práctica en Estados Unidos y en el mundo. Fundación Germán Sánchez Ruipérez, Madrid, 1992, pp. 78-82.

15 PIZARROSO QUINTERO, Alejandro: Op. cit., p. 35. 
flicto y le exige que detenga la agresión en Kosovo" (25-3-1999, p. 5), "La OTAN persigue destruir el ejército serbio si Milosevic no cede" (26-3-1999, portada); "La OTAN prepara una nueva escalada militar contra Milosevic" (11-4-1999, portada); "Milosevic amenaza con extender la guerra en los Balcanes tras el cierre de la frontera croata" (22-4-1999, p. 5).

La reiteración ${ }^{16}$ de estas afirmaciones y expresiones contribuye a que el medio difunda una imagen negativa de Milosevic, que es presentado al lector como una persona cruel e irracional que prefiere la guerra antes que la paz. Además, la personificación del conflicto llega a tal punto que en vez de hablar de tropas serbias o del ejército yugoslavo, se recurre con frecuencia a expresiones del tipo 'las fuerzas de Milosevic', con lo que el medio contribuye a crear un estereotipo negativo del serbio, encasillando a todos los serbios bajo la misma etiqueta.

Por su parte, siguiendo el mecanismo propagandístico de que el adversario es el único responsable de la guerra, los dirigentes yugoslavos también simplifican sus mensajes culpando a la OTAN de todos sus males. Sin embargo, estas declaraciones aparecen con menos frecuencia en El País, y cuando lo hacen quedan relegadas a los últimos párrafos del texto, aquellos que tienen menor importancia dentro de la estructura piramidal de la información, y a los que el lector prácticamente no accede, por lo que el medio corre el peligro de difundir sólo una determinada visión de lo acontecido, ofreciéndole al receptor un mensaje unidireccional.

A la personificación del adversario, Miguel Roiz ${ }^{17}$ añade otro proceso de simplificación, la reducción de las alternativas de orientación moral hacia la situación o acontecimiento, a dos situaciones antagónicas: la buena/la mala, la positiva/la negativa, la nuestra/la suya, etc., proceso al que aludiremos en las siguientes páginas.

\section{Exageración y desfiguración de los contenidos.}

Este mecanismo implica ofrecer únicamente los contenidos favorables al emisor, enfatizándolos al máximo, recurriendo incluso a la mentira (ya sea a través de la omisión y silencio de hechos noticiables o mediante la creación de sucesos o hechos que no existen). Por el contrario, el propagandista se limita a guardar silencio en aquellos puntos en los que está débil. Se trata de un procedimiento casi universal.

\footnotetext{
16 Domenach señala la repetición de una idea central como una de las reglas básicas de la propaganda (regla de la orquestación). En este sentido, Reyzábal reconoce que "la reiteración constante de ciertas cuestiones constituye un factor decisivo para que un determinado mensaje sea asimilado por el público, incluso cuando se trata de frases sin ningún contenido importante" (REYZÁBAL, María Victoria: Op. cit., p. 173).

17 ROIZ, Miguel: Técnicas modernas de persuasión. EUDEMA, Madrid, 1994, p. 54.
} 
144 Mecanismos básicos de la propaganda de guerra en los medios informativos.

El ejemplo de Kosovo

Según este principio, la información se seleccionará de tal manera que los hechos del enemigo se presenten como acciones negativas, que serán reiteradas y tratadas con múltiples detalles, mientras que nuestras actuaciones estarán impregnadas de rasgos positivos, y en los casos en los que afloren aspectos negativos, éstos serán tratados brevemente.

Eso es precisamente lo que sucedió en el conflicto de Kosovo, donde los medios occidentales aplicaron este principio haciéndonos creer que sólo el enemigo -los serbios- provoca atrocidades a propósito, mientras que los errores aliados son involuntarios. En concreto, El País publica informaciones donde el Gobierno yugoslavo y los serbios en general son protagonistas de acciones que se pueden calificar de negativas o 'malas'. Ellos son los que acaban con la información independiente cerrando emisoras de radio, periódicos y cadenas de televisión, y son los que cometen las mayores de las atrocidades con víctimas inocentes.

En muchas ocasiones se publican rumores sobre aspectos negativos del enemigo a través de determinadas fuentes, con lo que el medio crea un suceso que no existe y que cala en la opinión pública. De hecho, varias informaciones recogían testimonios imprecisos que sostenían que Milosevic había ordenado asesinar a los líderes albaneses moderados de Kosovo, quienes reaparecieron algunos días después, mientras que en otros textos se hablaba de la posible existencia de campos de concentración: "El ministro alemán de Defensa, Rudolf Scharping, denunció ayer que existen indicios de que el régimen serbio ha construido varios campos de concentración para encerrar en ellos a miles de kosovares. En esos centros se encontrarían los hombres que han sido separados de las mujeres y los niños cuando comenzaron los bombardeos y cuyo paradero no ha podido ser aclarado por nadie desde hace varios días" (1-4-1999. p. 5)

Por su parte, las 'malas' acciones de la OTAN son casi siempre justificadas por las atrocidades que comenten los serbios. Incluso la principal consecuencia de los bombardeos, la cuestión de los refugiados, se achaca única y exclusivamente a la 'limpieza étnica' cometida por los serbios, limpieza contra la que reaccionan los aliados.

De esta forma reaparece la retórica del periodo de la guerra fría: demostrar que la paz sólo es posible si interviene la OTAN y se aceptan sus condiciones. Así, los bombardeos se presentan como un mal menor y necesario: "El primer ministro italiano, Massimo D' Alema, justificó ayer en una comparecencia ante la Cámara de Diputados, los bombardeos de la OTAN sobre territorio de la ex Yugoslavia, señalando que la intervención era "necesaria e inevitable"” (27-3-1999, p. 9); "Blair formuló un emotivo llamamiento para apoyar la campaña durante un breve mensaje a la nación en el que explicó las razones de la participación británica. "De no haber actuado ahora no habría sido posible confinar el conflicto a las fronteras de Kosovo, y tendríamos una escalada con el consiguiente éxodo de centenares de miles de refugiados", dijo" (27-3-1999, p. 9); "Solana intervino 
ayer varias veces para defender que el éxodo no es consecuencia de la intervención aliada y que la huida de la población responde a una estrategia de limpieza étnica. "Si no hubiéramos atacado, la situación sería ahora igual o peor, y a lo mejor sería ya tarde para hacer algo para pararla", dijo" (29-3-1999, portada).

Incluso cuando la OTAN comienza a reconocer lo que denomina 'errores' de ataque, asegura que los civiles muertos eran 'escudos humanos' puestos por los serbios para provocar una matanza, con lo que le resta importancia a esas muertes que resultan molestas en el plano político. En estos casos, muchas informaciones no entrecomillan la palabra 'error', mostrando así su aceptación de los hechos aliados.

En cualquier caso, las declaraciones recogidas por El País insisten en que los 'errores' de la OTAN no son comparables a las atrocidades del régimen de Belgrado. Y, en ocasiones, el propio periodista deja entrever que los aliados hacen todo lo posible para evitar daños civiles, aunque no siempre sea posible: "Los misiles de la Alianza siempre llegan de madrugada, amparados en la oscuridad y con la intención evidente de reducir al máximo la posibilidad de causar daños entre la población" (6-4-1999, p. 2); "Pese al cuidado que ponen los aviadores en circunscribirse a los objetivos militares y/o estratégicos, cometen fallos" (10-41999, p. 6). De esta forma, las muertes provocadas por los aliados se amparan bajo el concepto de equivocaciones, mientras que los muertos causados por los serbios se convierten en crímenes brutales.

En definitiva, a través de todos estos mecanismos, un medio occidental como El País da por buenas todas las acciones aliadas, que son necesarias, aunque dolorosas, para acabar con lo que se presenta como un auténtico genocidio.

\section{La apelación a la emoción.}

La propaganda, y de forma más evidente en tiempos de conflictos bélicos, se basa en la emoción, que se convierte, como destaca Anne Morelli, en "el resorte utilizado permanentemente para movilizar a la opinión pública e incluso puede decirse que la propaganda y la emoción son y han sido siempre, consustanciales"18.

Precisamente los textos informativos consiguen persuadir a través de un discurso emotivo que hace referencia a los sentimientos primarios. De esta forma, se busca el asentimiento o rechazo hacia un tema concreto. La afectividad se manifiesta en el relato de los hechos y en las imágenes que se emplean, que generan el interés y el sentimiento compasivo del lector hacia aquellas víctimas que se consideran dignas de recibir un tratamiento informativo detallado.

18 MORELLI, Anne: Principios elementales de la propaganda de guerra (utilizables en caso de guerra fría, caliente o tibia). Argitaletxe HIRU, Hondarribia (Guipúzcoa), 2001, p. 115. 
146 Mecanismos básicos de la propaganda de guerra en los medios informativos.

El ejemplo de Kosovo

En el conflicto de Kosovo los refugiados albanokosovares se convirtieron en el nuevo elemento mediático que movilizó a la opinión pública occidental a favor de la intervención armada. Durante semanas, ni un solo telediario se abrió sin las imágenes impactantes de los refugiados y los testimonios de familias masacradas, mujeres que relataban las atrocidades padecidas, etc.

En los medios impresos las fotografías aportaron la mayor carga emotiva, sobre todo si tenemos en cuenta que las imágenes de refugiados eran las que predominaban (campos de refugiados, mujeres llorando, niños que juegan con los voluntarios, despliegue de ayuda humanitaria, deportados kosovares que esperan en la frontera con Albania o Macedonia, etc.). Sin embargo, hay sufrimientos que no se cuentan. Así, en el caso de El País es destacable la ausencia de la cobertura del sufrimiento de los serbios, turcos, montenegrinos y gitanos, el $15 \%$ de los ciudadanos de Kosovo que no son albaneses.

En cualquier caso, la publicación de fotografías emotivas contribuyeron en muchas ocasiones a justificar los ataques de la Alianza Atlántica. Así, es significativo que hasta el 28 de marzo El País no recoge imágenes conmovedoras sobre los refugiados, y lo hace justo al lado de un titular en el que se afirma que "La OTAN pasa a una nueva fase y ataca blancos móviles", y un subtítulo que nos da a entender que sólo así se puede responder a la represión que sufren los kosovares ("Los aliados responden a la creciente represión en Kosovo con la orden de destruir los tanques sobre el terrero"). La imagen en cuestión es un primer plano de una madre, cuyo rostro refleja una gran angustia, y que lleva a su hija pequeña en brazos. Además, si tenemos en cuenta que en el 27 de marzo las informaciones recogían las críticas de muchos políticos occidentales hacia los bombardeos, la publicación de esta imagen no puede ser más oportuna, ya que evidencia que la intervención es necesaria.

La utilización de determinados términos favorece también la carga emotiva de los mensajes. Al respecto, Brown ${ }^{19}$, destaca el recurso de sustituir nombres o términos neutrales por otros con connotaciones emocionales, como es el caso de 'rojo' en lugar de 'comunista'. A esta técnica se unen los relatos detallados de las matanzas y atrocidades atribuidas a los serbios, que se convierten en la encarnación del mismo mal. Los ejemplos más destacados publicados por El País son:

- "La policía serbia mató en los últimos días a sangre fría a veinte profesores en un pueblo de la provincia de mayoría albanesa, según relataron ayer testigos presenciales a las autoridades albanesas y al Alto Comisionado de Naciones Unidas para los Refugiados (ACNUR). Otra denuncia, no confirmada aún por fuentes independientes, informó ayer de otra matanza de treinta personas en Suva Reka. En varias aldeas, según testigos, la policía serbia ha aprovechado la salida

19 BROWN, J.A.C.: Op, cit., p. 25. 
de los observadores de la Organización para la Seguridad y la Cooperación en Europa (OSCE) para quemar las casas de los albaneses y obligarles a huir" (273-1999, portada).

- "La limpieza étnica ha empezado a llegar también a núcleos urbanos. Familias enteras han sido separadas: las mujeres y los niños normalmente han sido enviados hacia las fronteras con Albania y Macedonia mientras los hombres mayores de 16 años en muchos casos han sido ejecutados en fusilamientos sumarios" (29-3-1999, p. 2.).

- "El mecanismo de la limpieza étnica tiene tres fases. "Al principio, las fuerzas serbias rodean un barrio determinado de la ciudad y empiezan a bombardearlo, sin prisa, sin precipitación", prosiguió. (...) Entonces se despliega la segunda fase. "Los tanques, los vehículos policiales, los temidos hombres de uniforme negro de Zeljko Raznatovic, Arkan, se aproximan a las viviendas. Grupos de gitanos colaboran con ellos como informadores. Con altavoces, conminan a los kosovares a salir de sus casas. Las alternativas que ofrecen son tajantes: o rendición, o muerte segura". (...) Tras la rendición, los serbios seleccionan. Unos pocos, cuidadosamente elegidos -generalmente vinculados con la guerrilla o con partidos políticos: la información de que disponen es buena-, son ejecutados sobre la marcha o apartados del resto del grupo. Después saquean las casas y, en muchos casos, las incendian. Los prisioneros son conducidos al estadio de fútbol de Prístina" (2-4-1999, p. 7).

Estas atrocidades son redactadas como hechos ocurridos realmente, aunque en muchas ocasiones se reconoce que no están confirmadas. Sin embargo, al presentarlas como hechos, se contribuye a un modelo de propaganda en el que los serbios son el enemigo, los únicos responsables de los bombardeos de la OTAN, de las huidas de albanokosovares a países limítrofes y de las matanzas que relatan los desplazados.

\section{Tratamiento desequilibrado de las fuentes.}

El control y la selección de la información son dos de las tareas básicas utilizadas por el propagandista, sobre todo en tiempos de guerra. Estas tareas se traducen principalmente en un tratamiento desequilibrado de las fuentes de información, que se vuelve más acusado, según Borrat, "cuando es un conflicto entre A, miembro del mismo bloque occidental, y B, miembro del bloque opuesto o de la periferia: sobreabundan entonces las fuentes de A, y faltan o escasean las de B, que cuando se dan tienden a ubicarse tan sólo en la disidencia o la oposición" ${ }^{20}$.

20 BORRAT, Héctor: El periódico, actor político. Editorial Gustavo Gili. Barcelona, 1989, p. 94. 
148 Mecanismos básicos de la propaganda de guerra en los medios informativos.

El ejemplo de Kosovo

Se trata, pues, de un recurso propagandístico esencial por el que se silencian aquellas fuentes que ofrecen un análisis alternativo a las fuentes oficiales y, por lo tanto, se contribuye a dar una visión concreta de los acontecimientos.

Chomsky y Herman destacan que los medios de comunicación le conceden gran importancia a las fuentes oficiales porque ellos mismos se definen como proveedores 'objetivos' de noticias. "En parte para mantener esa imagen de objetividad, y en parte para protegerse de críticas de parcialidad y de la amenaza de procesos por difamación, necesitan material que pueda mostrarse como presuntamente correcto" 21 .

En tiempos de conflictos bélicos, este tratamiento puede ser fruto de la dependencia de los corresponsales a los servicios de información de los ejércitos, que saturan a los periodistas con gran cantidad de datos (generalmente de tipo técnico) para que no tengan que buscarlos fuera, así como a la selección de periodistas realizada por los militares en los denominados pools.

En cualquier caso, el predominio de unas fuentes y no otras evidencia una intención por parte del medio que las publica. Durante el conflicto de Kosovo, la inmensa mayoría de las fuentes citadas expresamente por El País correspondían a miembros de la OTAN, que ocupaban un lugar destacado dentro de la estructura de la información. Sin embargo, como hemos apuntado, las fuentes serbias o aquellas que incidían en aspectos negativos de los aliados aparecían relegadas a un segundo plano. En pocas ocasiones se detallan informaciones del Gobierno yugoslavo, (por ejemplo, una lista de destrucciones civiles), siempre se mencionan de forma generalizada y como si se pusiese en cuestión lo que se afirma. Por tanto, la tendencia general es cuestionar la información procedente de fuentes serbias, mientras que las fuentes atlánticas no van acompañadas de expresiones que ponen en duda los datos que aportan.

Dentro del apartado de las fuentes, destacan dos recursos propagandísticos frecuentes en los medios de comunicación: Hablar a través de otras fuentes y la autoridad vaga. El primero de ellos recurre a fuentes militares y a los testimonios de los refugiados para insistir en las masacres y deportaciones serbias, lo que supone una justificación del ataque aliado.

Por su parte, la autoridad vaga consiste en afirmar hechos a través de fuentes que no son identificadas. Este uso puede responder al deseo expreso de las fuentes, pero también puede deberse al interés del periodista por publicar un hecho que no está confirmado bajo la declaración indirecta de una de estas fuentes imprecisas. El uso habitual de este recurso, evidencia una manipulación por parte del medio, que no ofrece al lector una información precisa y contrastada.

21 CHOMSKY, Noam y HERMAN, Edward: Los guardianes de la libertad. Propaganda, desinformación y consenso en los medios de comunicación de masas. Editorial Crítica, Barcelona, 1990, pp. 51-52. 
En el caso del conflicto de Kosovo, este recurso es especialmente peligroso cuando se afirman asesinatos cometidos por los serbios: "Diplomáticos occidentales afirman que ha sido asesinado Latif Berisha, un conocido político local. Las mismas fuentes aseguran que en todo Kosovo se ha desatado la caza de los defensores de los derechos civiles y aseguran que dos de los guardaespaldas del embajador William Walker han sido asesinados" (29-3-1999, p.2); "Portavoces aliados denunciaron ayer que las fuerzas serbias "dispararon con armas pesadas a columnas de refugiados albanokosovares "” (1-4-1999, p. 2).

\section{A modo de conclusión}

Los medios de comunicación utilizan recursos propagandísticos en sus mensajes con el fin de persuadir a los lectores. Esta utilización resulta inseparable de las informaciones sobre conflictos bélicos, pues en estos casos la información corre el riesgo de convertirse en propaganda, y en muchas ocasiones es un fenómeno inseparable de ella.

La simplificación de la información, la exageración y desfiguración de los contenidos, la apelación a la emoción y el tratamiento desequilibrado de las fuentes, son los cuatro pilares sobre los que se sustenta la información en tiempos de guerra. El empleo de estos mecanismos favorece que el medio de comunicación transmita una imagen unidireccional, como sucedió en el conflicto de Kosovo de 1999 con el predominio de fuentes militares y oficiales de la Alianza Atlántica.

En primer lugar el medio identifica a un enemigo sobre el que recae toda la culpa, léase en nuestro caso los serbios, y en función de este principio se ofrece una información esquematizada en un mundo de 'buenos' y 'malos' (OTANMilosevic). Una vez identificado el enemigo se personifica en él todas las atrocidades cometidas sobre las víctimas (los albanokosovares) y esas acciones negativas se repiten una y otra vez para que el mensaje sea asimilado por la opinión pública. Por su parte, nuestro bando -la OTAN- se presenta como héroe, incluso sus 'errores' no son tratados con la intensidad y el tono negativo de las acciones enemigas.

La carga emotiva contenida en los mensajes adquiere un gran poder de persuasión y contribuye a justificar determinadas acciones. Y esa carga emotiva se consigue recurriendo a los sentimientos primarios de los hombres y utilizando imágenes conmovedoras de víctimas inocentes. De esta forma los medios adquieren el consentimiento de la población para intervenir militarmente en cualquier conflicto que les interese, pues la propaganda hace creer a la opinión pública que, al contrario que nuestros enemigos, nosotros hacemos la guerra por motivos honorables. 